\title{
Presencia de Histoplasma capsulatum en Heces de Palomas Mensajeras y de Castilla en la Ciudad de Lima, Perú
}

\author{
Presence of Histoplasma capsulatum in Faeces of Homing Pigeons and Rock \\ Pigeons in Lima, Peru \\ Yurie Arias G. ${ }^{1}$, Siever Morales C., ${ }^{2,3}$, Eglinton Villacaqui A. ${ }^{1}$
}

\section{Resumen}

El hongo Histoplasma capsulatum es el agente causal de la histoplasmosis, enfermedad de importancia en salud pública. El objetivo del presente estudio fue determinar su presencia en las heces de palomas domésticas (Columba livia) en la ciudad de Lima, Perú. Se recolectaron muestras de excretas de 245 palomas de Castilla y palomas mensajeras. Las muestras fueron sembradas en agar Sabouraud e incubadas a 37 y a $28{ }^{\circ} \mathrm{C}$ durante 2 a 4 semanas aproximadamente, y las colonias fueron identificadas por sus características macroscópicas y microscópicas. El 0.41\% (1/245) de las muestras fueron positivas a $H$. capsulatum, en tanto que el programa de simulación estocástica beta-pert (@Risk) determinó una prevalencia mínima de $0.369 \%$ y máxima de $0.451 \%$.

Palabras clave: Histoplasma capsulatum; palomas domésticas; salud pública

\section{Abstract}

The fungus Histoplasma capsulatum is the causative agent of histoplasmosis, disease of public health importance. The aim of this study was to determine its presence in faeces of domestic pigeons (Columba livia) in the city of Lima, Peru. Faecal samples $(n=245)$ were collected, processed and cultivated in Sabouraud agar at 37 and $28^{\circ} \mathrm{C}$ for 2 to 4 weeks approximately. The colonies were identified by macroscopic and microscopic

\footnotetext{
${ }^{1}$ Laboratorio de Microbiología, Facultad de Medicina Veterinaria y Zootecnia, Universidad Cientifica del Sur, Lima, Perú

${ }^{2}$ Laboratorio de Microbiología y Parasitología Veterinaria, Facultad de Medicina Veterinaria, Universidad Nacional Mayor de San Marcos, Lima, Perú

${ }^{3}$ Email: sieverm@hotmail.com
}

Recibido: 28 de julio de 2016

Aceptado para publicación: 24 de febrero de 2017 
characteristics. Only $0.41 \%(1 / 245)$ of samples were positive to $H$. capsulatum, while the beta-pert (@Risk) stochastic simulation showed a minimum prevalence of $0.369 \%$ and a maximum prevalence of $0.451 \%$.

Key words: Histoplasma capsulatum; domestic pigeons; public health

\section{INTRODUCCIÓN}

La paloma doméstica (Columba livia) es una especie considerada como parte de la fauna de muchas áreas urbanas (Styles y Skutch, 1998), de manera que su población ha ido creciendo de manera exponencial alrededor del mundo (Ali et al., 2013). Actualmente, es considerada como una plaga por el daño que generan sus heces en las edificaciones y monumentos históricos, así como por la posibilidad de poder transmitir diversas enfermedades de importancia en salud pública (Ramírez et al., 2008), entre ellas, la histoplasmosis, enfermedad fúngica de importancia, principalmente en pacientes inmunocomprometidos (López, 2006).

La histoplasmosis es también conocida como la enfermedad de Darling, histoplasmosis americana, citomicosis, reticuloendoteliosis, enfermedad de los murciélagos, enfermedad de las cuevas, fiebre de las cavernas y minas, fiebre de Tingo María y enfermedad del valle de Ohio (Sánchez et al., 2010). Puede ser considerada como homóloga en cierto sentido a la tuberculosis, ya que el Histoplasma capsulatum y el Mycobacterium tuberculosis usan a los macrófagos como células hospedadoras y pueden generar infecciones agudas, persistentes o potencialmente diseminadas (Woods, 2002).

La enfermedad es causada por el hongo Histoplasma capsulatum. Este hongo habita usualmente en el ambiente, pero se le reporta principalmente en suelos con excretas de aves o murciélagos (Acha y Szyfres, 2001). Su característica principal es su dimorfismo, porque a temperaturas bajas (medio ambiente) se encuentra en su fase de micelio, pero a $37^{\circ} \mathrm{C}$ (temperatura corporal de un mamífero) desarrolla su fase levaduriforme.

La vía de entrada al organismo es a través del aparato respiratorio, ya que es por donde ingresan las conidias por aerosolización; sin embargo, también hay casos de ingreso vía cutánea, generando una lesión limitada en la piel (Sánchez et al., 2010). El periodo de incubación es entre 1 a 3 semanas, pero cuando la infección es hiperaguda puede desarrollarse entre 1 y 3 días (López, 2006).

Existen diversas técnicas para diagnosticar la enfermedad, desde métodos directos y convencionales hasta métodos de nivel molecular; entre ellas, el examen en fresco con diferentes coloraciones (Muñoz et al., 2010), cultivo microbiológico (Gutiérrez et al., 2014), hemocultivo por lisis centrifugación (Muñoz et al., 2010), fijación de complemento e inmunodifusión en agar gel, ELISA directa e indirecta (Kauffman, 2007; Muñoz et al., 2010), antígeno urinario (Sánchez et al., 2010), prueba cutánea de la histoplasmina (Torres et al., 2000), PCR (Kauffman, 2009) $\mathrm{y}$ rayos X (Conces et al., 2014).

Por todo ello, el objetivo del presente estudio fue determinar la presencia del hongo Histoplasma capsulatum en las heces de las palomas domésticas (C. livia) de la ciudad de Lima, Perú por su importancia en la salud pública. 
Materiales y Métodos

\section{Lugar de Estudio}

El trabajo de investigación se realizó en la provincia y departamento de Lima, Perú. El clima es variado, templado, húmedo y con alta nubosidad en invierno en la zona costera, donde las precipitaciones son escasas a ligeras (INEI, 2000).

\section{Población y Muestra}

Se trabajó con dos tipos de poblaciones: finita (palomas mensajeras) y no finita (palomas de Castilla). Para el caso de la determinación de la población no finita $(\mathrm{n}=20)$ se utilizó la siguiente fórmula, donde se usó el $1.3 \%$ de prevalencia referencial, reportado por Cermeño et al. (2006) para $H$. capsulatum en palomas de Castilla:

$$
n=\frac{z^{2} \frac{\alpha}{2} p(1-p)}{E^{2}} \longrightarrow \frac{(1.96)^{2} \times 0.013(1-0.013)}{(0.05)^{2}}
$$

Para la determinación de la población finita de palomas mensajeras $(n=20)$, se utilizó la siguiente fórmula, considerando una prevalencia referencial de $1.3 \%$ y una población aproximada de 3000 ejemplares (dato obtenido de la Asociación de Colombófilos del Perú).

$n=\frac{Z^{2} \alpha / 2 p(1-p) N}{(N-1) E^{2}+Z^{2} \alpha / 2 p(1-p)} \rightarrow \frac{(1.96)^{2} \times 0.013(1-0.013)(3000)}{(3000-1)(0.05)^{2}+(1.96)^{2} \times 0.013(1-0.013)}$

Pese a la $n$ de 20 individuos por tipo de paloma, se trabajó con 126 muestras de palomas de Castilla y 119 muestras de palomas mensajeras, utilizando en ambos casos el método de selección de muestra de tipo dirigida. Las muestras para el primer tipo de palomas se recolectaron del suelo, siendo seleccionadas por el área más cercana de anidación, y en el segundo caso, de los palomares. Las muestras, asimismo, debían estar secas, condición necesaria para la presencia del hongo.
Los lugares de obtención de muestras para las palomas de Castilla fueron las iglesias del centro histórico de Lima (locales 1 al 6), de allí que se asume que las muestras de heces fueron de palomas. Asimismo, las muestras de las palomas mensajeras fueron obtenidas de cuatro palomares de la zona.

Las muestras (20 g) se recolectaron entre los meses de setiembre a diciembre de 2015, utilizando bolsas plásticas con cierre hermético. Las muestras fueron remitidas al Laboratorio de Microbiología de la Universidad Científica del Sur (Lima), para ser procesadas el mismo día. En la toma y procesamiento de las muestras se tomaron las medidas de bioseguridad correspondientes, incluyendo el uso de mascarillas descartables FFP2 CV-Segre, mameluco descartable Dupont y guantes desechables Ansell (Sekur, Perú).

\section{Procesamiento de las Muestras}

El procesamiento de las muestras se realizó en base a la técnica descrita por Cermeño (2006), donde las heces fueron mezcladas con solución salina estéril en una concentración de 1:10 durante 5 min con un homogenizador. Luego, dicha solución se dejó reposar durante $30 \mathrm{~min}$, retirándose una alícuota de $0.1 \mathrm{ml}$ del sobrenadante y sembrada en agar Sabouraud. Con base a la característica dimórfica del hongo, se prepararon dos tubos por muestra, donde uno fue incubado a $37^{\circ} \mathrm{C}$ y el otro a temperatura ambiente (alrededor de $24{ }^{\circ} \mathrm{C}$ ). La observación se realizó diariamente, hasta un tiempo máximo de 56 días de incubación.

El hongo fue identificado por sus características macroscópicas (forma, color, tiempo de crecimiento) y características microscópicas (Muñoz et al., 2010). Para el crecimiento en forma de levadura, se colocó la colonia en una gota de lactofenol en una lámina portaobjetos, se mezcló hasta obtener una solución uniforme, se cubrió con una lámina cubreobjetos y observó en el microscopio a $100 \mathrm{X}$, donde según sus características 


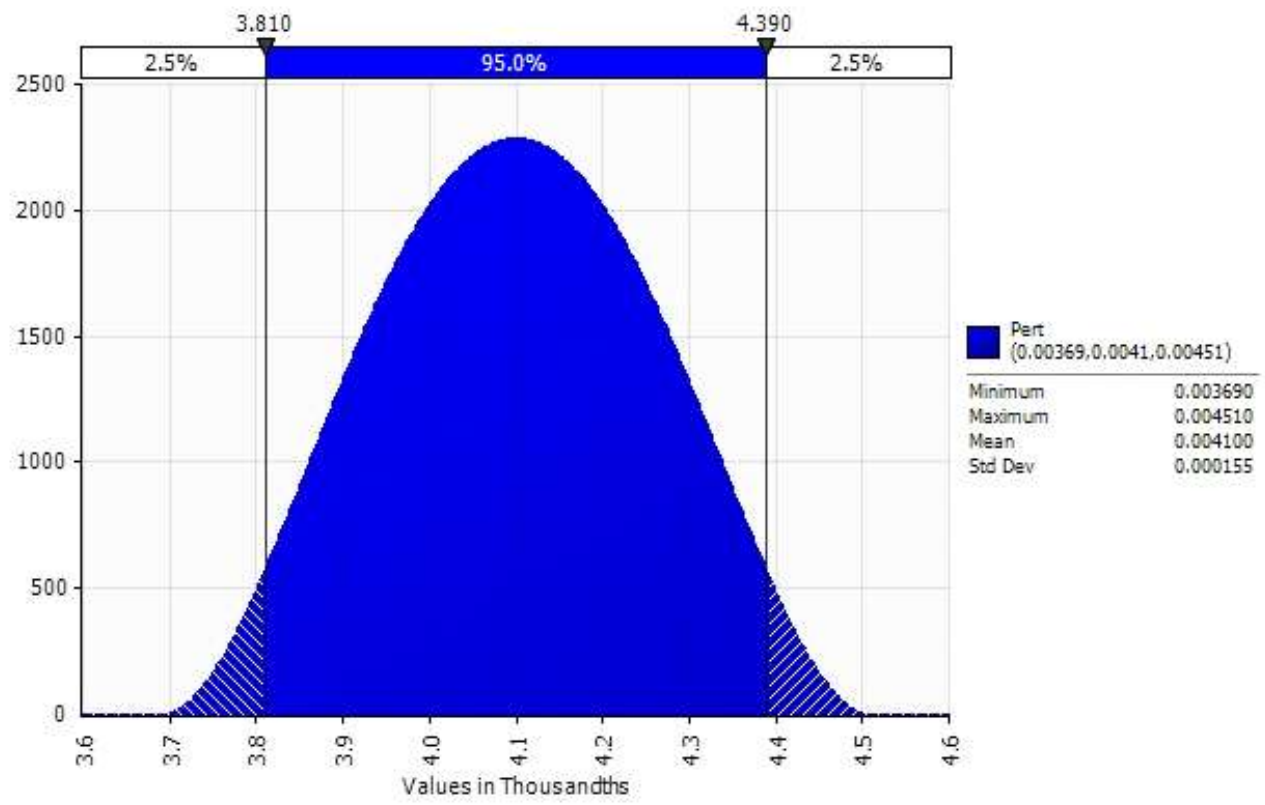

Figura 1. Distribución de la prevalencia del hongo Histoplasma capsulatum por distribución estocástica beta-pert (@Risk) en muestras de heces de palomas de Castilla y palomas mensajeras $(n=245)$ en la ciudad de Lima, Perú (2015)

morfológicas se realizaron pruebas adicionales (tinta china, prueba de urea) para identificar la especie. Cuando la colonia presentó crecimiento tipo moho, se hizo una impronta con cinta adhesiva sobre una lámina portaobjetos que contenía una gota de lactofenol, y se observó en el microscopio a $40 \mathrm{X}$ y a $100 \mathrm{X}$ para observar la presencia de un conidióforo que permita identificar la especie.

\section{Análisis de Datos}

Se obtuvo el porcentaje de presentación del $H$. capsulatum en base a las 245 muestras recolectadas y se utilizó el programa de simulación estocástica Beta-pert (@Risk).

\section{Resultados}

Se recolectaron 30, 12, 30, 13, 24 y 17 muestras de heces de palomas de Castilla en los seis locales (iglesias), mientras que fueron $30,24,31$ y 34 muestras que se recolectaron en los cuatro palomares.
El $0.41 \%(1 / 245)$ de las muestras fue positiva a la presencia de $H$. capsulatum, la cual correspondió a una muestra de heces de paloma de Castilla. La muestra positiva desarrolló en el cultivo a $37^{\circ} \mathrm{C}$ y fue de tipo filamentoso. El modelo de simulaciones estocásticas de distribución beta demostró una prevalencia mínima de $0.36 \%$ y una máxima de $0.45 \%$ (Figura 1 ).

\section{DiscuSión}

En el presente estudio, las muestras fueron recolectadas en ambientes vinculados a las áreas de anidación y fueron cultivadas en agar Sabouraud para proceder a la identificación micológica. Para el diagnóstico de la histoplasmosis se dispone de diversas pruebas; no obstante, la prueba «gold standard» es el cultivo microbiológico (Gutiérrez et al., 2014), prueba que fue utilizada en el presente estudio. Asimismo, las heces secas presentan mayor cantidad de nitrógeno y fosfatos, lo cual favorece el crecimiento del hongo (Menges y Habermann, 1955). 
El hongo $H$. capsulatum ha sido reportado en dos cuevas de Venezuela y Perú, y en Ciudad Bolívar (Venezuela). En el caso de las cuevas, las muestras de heces fueron de guácharos, llamados también aves de las cavernas (Steatornis caripensis); estas muestras fueron sembradas en agar Sabouraud y el sobrenadante obtenido fue inoculado en ratones, encontrándose $13.3 \%$ (2/15) (Ajello et al., 1960) y 68.75\% (11/16) (Lazarus y Ajello, 1955). En el caso de Ciudad Bolívar, las muestras fueron recogidas en diversas localidades de la ciudad donde anidaban las palomas de Castilla, encontrándose una prevalencia de $1.3 \%(1 / 116)$ (Gutiérrez et al., 2014). El 0.41\% (1/245) de positivos del presente estudio fue menor a los reportes mencionados, probablemente debido a la recolección de muestras en los meses de setiembre y octubre, donde la temperatura se encuentra en $16-17^{\circ} \mathrm{C}$.

El Histoplasma capsulatum es un hongo dimórfico; es decir, se desarrolla de acuerdo a la temperatura en que se encuentra. Mayormente crece de manera saprófita en climas tropicales y subtropicales, donde la temperatura oscila entre 22 y $29^{\circ} \mathrm{C}$ (Fernández et al., 2011). En el laboratorio, cuando es cultivado e incubado entre $28 \mathrm{y}$ $37^{\circ} \mathrm{C}$ se puede observar su fase filamentosa (López, 2006). Es así, que en este estudio la muestra positiva se desarrolló en el tubo incubado a $37^{\circ} \mathrm{C}$. No obstante, otros autores afirman que el crecimiento se da principalmente a temperaturas menores a $37{ }^{\circ} \mathrm{C}$ (Medoff et al., 1987; Weaver et al., 1996; Acha y Szyfres, 2001; Woods, 2002).

El hongo que se desarrolló en la muestra positiva se hizo evidente a partir de las 48 horas de incubación; sin embargo, la colonia creció junto con otras especies de hongos. Por tal motivo, una vez que pudo ser confirmada como H. capsulatum, ya no pudo continuar desarrollando pues otras especies, como el Rhizopus sp, invadieron el área de crecimiento, agotando el sustrato disponible. De acuerdo a Goos (1964), el hongo difícilmente crece en menos de 24 horas de incubación y, además, otros hongos del ambiente que crecen más rápido pueden inhibir su crecimiento.

\section{Conclusiones}

- Histoplasma capsulatum está presente en heces de palomas domésticas (Columba livia) en la ciudad de Lima con una frecuencia de $0.41 \%$.

- El programa de simulación estocástica beta-pert (@Risk)determinó una prevalencia mínima de $0.369 \%$ y máxima de $0.451 \%$ de $H$. capsulatum en heces de palomas domésticas en la ciudad de Lima.

\section{Literatura Citada}

1. Acha P, Szyfres B. 2001. Zoonosis y enfermedades transmisibles comunes al hombre y a los animales. $3^{\text {a }}$ ed. Washington: Organización Panamericana de la Salud. 398 p.

2. Ajello L, Briceño-Maaz T, Campins H, Moore J. 1960. Isolation of Histoplasma capsulatum from an oil bird (Steatornis caripensis) cave in Venezuela. Mycopathologia 12: 199-206. doi: 10.1007/BF02051369

3. Ali S, Allah B, Hussain I, Sajid M, Rafique M. 2013. Ecology of feral pigeon (Columba livia) in urban areas of Rawalpindi/Islamabad, Pakistan. Pakistan J Zool 45: 1229-1234.

4. Cermeño J, Hernández I, Cabello I, Orellán Y, Cermeño JJ, Albornoz R, Padrón E, Godoy G 2006. Criptococcus neoformans and Histoplasma capsulatum in dove's (Columbia livia) excreta in Bolívar State, Venezuela. Rev Latinoam Microbiol 48(1): 6-9.

5. Conces D, Stockberger S, Tarver R, Wheat L. 2014. Disseminated histoplasmosis in AIDS: finding on chest radiographs. AJR Am J Roentgenol 160: 15-19. doi: 10.2214/ajr.160.1.8416614 
6. Fernández C, Illnat M, Martínez G, Perurena M, Monroy E. 2011. Una actualización acerca de histoplasmosis. Rev Cubana Med Trop 63: 189-205.

7. Goos R. 1964. Germination of the macroconidium of Histoplasma capsulatum. Mycologia 56: 662-671. doi: $10.2307 / 3756617$

8. Gutiérrez S, Flores O, Alonso D, Macías R, Espino E. 2014. Enfermedad del viajero. Histoplasmosis diseminada en paciente inmunocompetente. Med Int Méx 30: 335-338.

9. [INEI] Instituto Nacional de Estadística e Informática. 2000. Departamento de Lima: Características de la infraestructura social y económica distrital: 1999. [Internet]. Disponible en: https:// ww w. inei.gob.pe/media/ MenuRecursivo/publicaciones_digitales/ Est/Lib0510/Libro.pdf

10. Kauffman C. 2007. Histoplasmosis: a clinical and laboratory update. Clin Microbiol Rev 20: 115-132. doi: 10.1128/ CMR.00027-06

11. Kauffman C. 2009. Histoplasmosis. Clin Chest Med 20: 115-132. doi: 10.1016/j.ccm.2009.02.002

12. Lazarus A, Ajello L. 1955. Aislamiento de Histoplasma capsulatum del suelo de una cueva en el Perú. Rev Per Med Exp Salud Pública 9: 5-12.

13. López C. 2006. Dimorfismo y patogenia de Histoplasma capsulatum. Rev Argent Microbiol 38: 235-242.

14. Medoff G, Kobayashi G, Painter A, Travis S. 1987. Morphogenesis and pathogenicity of Histoplasma capsulatum. Infect Immun 55: 1355-1358.

15. Menges R, Habermann R. 1955. Experimental avian histoplasmosis. Am J Vet Res 16: 314-320.
16. Monroy E, Fernández C, Díaz R, Martínez G, Illnait M, Perurena M. 2014. Evaluación de cuatro métodos de extracción del ADN de Histoplasma capsulatum y su uso en reacciones de PCR. Vaccimotor 23(2): 49-56.

17. Muñoz C, Cano L, González A. 2010. Detección e identificación de Histoplasma capsulatum por el laboratorio: de los métodos convencionales a las pruebas moleculares. Infectio 14(S2): $\mathrm{S} 145-\mathrm{S} 158$.

18. Ramírez O, Amador M, Camacho L, Carranza I, Chaves E, Moya A, Vega $M$, et al. 2008. Conocimiento popular de la paloma de Castilla (Columba livia) en el parque central de Alajuela. Zeledonia 12(1): 14-19.

19. Sánchez-Saldã̃a L, Galarza C, Cortéz F. 2010. Infecciones micóticas sistémicas o profundas: histoplasmosis. Dermatol Perú 20: 139-152.

20. Styles G, Skutch A. 1998. Guía de aves de Costa Rica. Santo Domingo de Heredia: InBio. 580 p.

21. Torres J, Ribas E, Gascón J, López O, Espasa M. 2000. Utilidad diagnóstica de la prueba intradérmica con histoplasmina, en áreas no endémicas de histoplasmosis. Rev Iberoam Micol 17: 97-101.

22. Weaver C, Sheehan K, Keath E. 1996. Localization of a yeast-phase-specific gene product to the cell wall in Histoplasma capsulatum. Infect Immun 64:3048-3054.

23. Woods J. 2002. Histoplasma capsulatum molecular genetics, pathogenesis, and responsiveness to its environment. Fungal Genet Biol 35: 8197. doi: 10.1006/fgbi.2001.1311 